\title{
Effect of Semi-Apical Angle on the Crush Mechanics of Metallic Bi-Tubular Tubes under Dynamic Axial Loading
}

\author{
Muhammad Kamran ${ }^{1}$, Xue Pu ${ }^{1}$, Naveed Ahmed ${ }^{1}$, \\ Ahmad Abdul Ghaffar Hanif ${ }^{2}$
}

\author{
${ }^{1}$ School of Aeronautics, Northwestern Polytechnical University, Xi'an, Shaanxi, China. \\ ${ }^{2}$ CESAT, Islamabad, Islamabad, Pakistan. \\ e-mail:kamranm470@yahoo.com,p.xue@nwpu.edu.cn, engineer_naveed@yahoo.com,ahmad.abdul.ghaffar@gmail.com
}

\begin{abstract}
Aerospace and automotive industrial advancement demands high energy absorbing structures for the human and equipement safety during transportaion and accidental emergencies. Thin-walled metallic tubes applications in the structures serve the purpose by absorbing energy during such dynamic scenarios. A new concept is presented in this study, involving bi-tubular tube with outer straight cylinderical tube and inner tube with semi-apical angle and response is monitored for dynamic axial loading. The outer and inner tubes are connected with 4 straight stiffeners. The inner tube semi-apical angle named as $\beta$ is varied from zero to 2 degrees and its sensitivity in energy absorption is studied.In total five configurations are studied with first configuration having $\beta$ as zero degree. The second and third configuration are with $\beta$ as one degree with distinct feature that in third configuration the tube is inverted. Same is true for the fourth and fifth configuration with $\beta$ as two degrees. The mass in each configuration is kept constant by adjusting the thickness of the stiffeners. Deformation modes, specific energy absorption and crushing force efficiency are determined for each configuration and contribution of $\beta$ is discussed. An analytical approach to observe the sensitivity of $\beta$ is also presented. The results are compared with the experimental and theoratical results to show the effectiveness of the proposed configurations.
\end{abstract}

Keywords:Bi-tubular, Semi-ApicalAngle, Energy Absorption, Dynamic Axial Loading.

\section{INTRODUCTION}

Thin-walled metallic tubes are highly efficient energy absorbers and are widely applied in engineering fields to dissipate the kinetic energy under dynamic loading. An ideal energy absorber should resist impact loads without causing a complete instant failure, and dissipate impact energy with controllable deformation [1]. Energy absorber capacity of an energy absorber is dependent on material properties, cross-section configurations, wall thickness and boundary conditions. Simulation methods can be a practical solution to investigate all of these factors as physical crash testing is a costly job [2-4].

Theoretical, numerical and experimental evaluation of energy absorption characteristics of metal columns with varying cross-sections like circular [5,6], square and hexagonal $[7,8]$ are studied under axial impact loadings. Circular tubes have been a consistent choice for energy absorption applications because of high strength and stiffness with low cost and ease of manufacturing. They absorb the energy by deforming themselves in different kind of deformation modes like locally deformed axisymmetric or concertina mode, non-symmetric or diamond mode, mixed mode or globally deformed Euler buckling mode under axial crushing depending on the geometrical, material parameters and boundary conditions [9].

Multi-cell tubes got special attention in recent years because of superior energy absorption due to increasing number of cells and intersection points [10] and has a wide applications scope from automotive structures [11] to train buffers [12] to helicopters subfloors [13]. Theoretical solutions under axial crushing to calculate the mean crushing load for the single-cell, double-cell and triple-cell square sections are derived and it is proved that multi-cell tubes posed higher energy absorption as compared to single-cell columns [14]. Numerical and experimental studies of dynamic axial impact response of different configurations of multicell columns showed that the crush force efficiency of the middle ribs (MR) multi-cell columns was the highest because it had the highest number of interaction between the inner and outer walls [15]. Along with circular tubes, many researchers investigated theSpecific Energy Absorption (SEA)for multi-cell thin-walled 
columns with different cross sections such as triangular, hexagonal and octagonal sections reporting that the Energy Absorption (EA)values of multi-cell sections with different cross sections were significantly higher than that of single- cell sections and increasing the number of cells increases the SEA [16-19].

Thin-walled conical tubes achieve different crushing modes based on their length and cross-section dimensions under crushing load. They collapse either in axisymmetric mode (concertina or ring mode) or non-axisymmetric mode (diamond mode) or mixed mode [20]. Energy dissipation rate is concentrated over relatively narrow zones and energy absorption is usually by progressive buckling of tubes walls. A parametric study on foam-filled conical tubes showed that they collapse in a stable manner with more lobes in comparison to empty tubes [21]. Flat-topped conical cells made of textile composites were analyzed and compared with theoretical and experimental solution with good agreement [22]. Very recently, a newly developed foam filled bi-tubular configuration is studied under dynamic axial and oblique loading in which the outer tube is kept circular while the inner tube is conical in shape [23]. Crashworthiness simulation showed a higher energy absorption in this configuration as compared to earlier bi-tubular designs. Numerical and experimental energy absorption studies for tapered multi-celled tubes revealed that the increase of the taper angle, the wall thickness and the number of cells in the cross section would enrich the crashworthiness capacity of the structure [24].Bi-tubular configurations are generally investigated for energy absorption using foam filled configurations. Numerical and experimental studies of foam filled single and bi-tubular circular tubes has shown that filling foam has no significanteffect on the improvement of bi-tubular tubes crashworthiness characteristics [25] while contrary to that other studies has shown considerable improvements with respect to energy absorption with foam filling particularly in bi-tubular configurations[26].

Tubes can be a useful energy absorption structure in high speed impact cases such as of trains and road vehicles for passive safety in order to reduce fatalities and human injuries. The train frontal body structure is improved by Salimi [27] by using thin walled tubes for the controlled deformation of the structure. Figure 1(a) shows the rail accidents with crash and derailing being the peak source of accidents while Figure 1(b) shows the improvement in the structure using thin walled tubes.

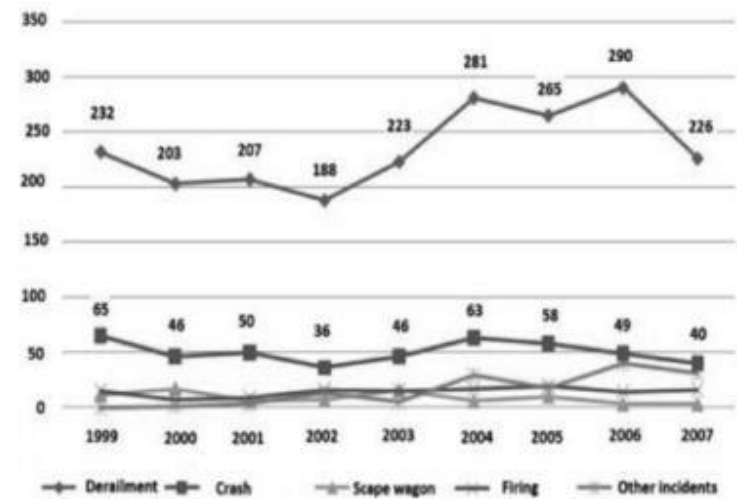

(a)

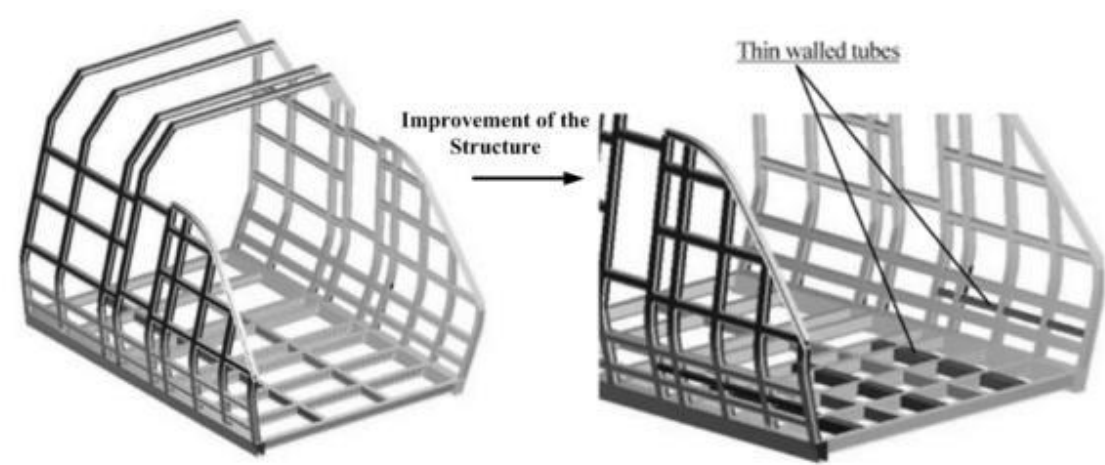

(b)

Figure 1: (a) Rail accidents (1997-2007) (b) Structure improvement using thin walled tubes[26]. 
The road accidents have also a major source of high speed impact fatalities as shown in Figure 2 for one year fatalities by type of crash. Thin wall structures can be a solution to improve the crashworthiness performance of door and frontal crash box during accidents. The objective in these studies is to reduce the weight and improve the crash performance with optimal values of crash parameters.

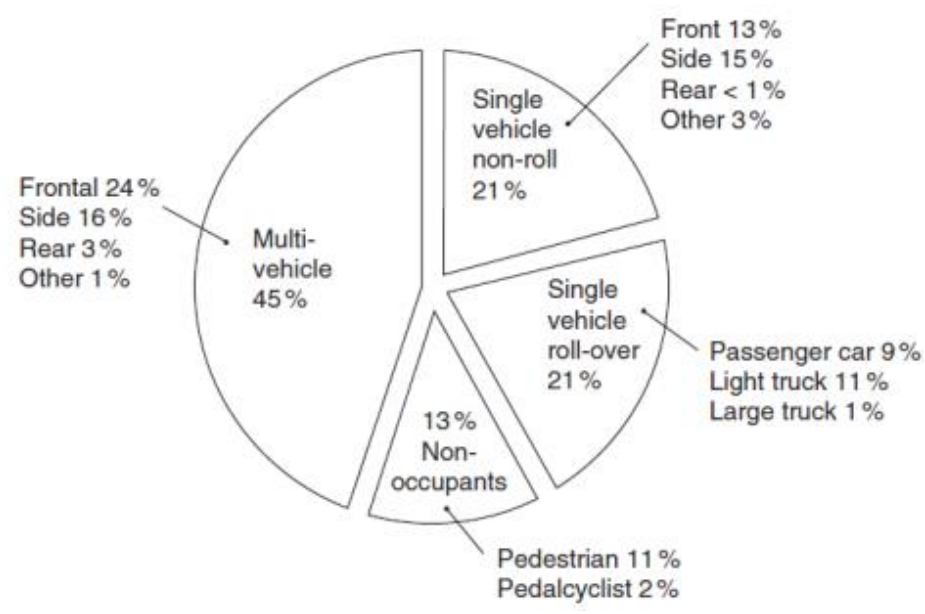

Figure 2:Fatalities in USA during year 2000 by type of crash (\%) [3]

In this study, a new bi-tubular configuration, unique in the nature that inner tube is having a semiapical angle and both the outer circular and inner conical tube are connected with four cross-walled stiffeners is presented. The tubes are impacted to investigate the dynamic response of proposed bi-tubular configuration under axial loading. The proposed configuration is multi-cell in nature and can be classified with the semiapical angle of the inner tube with vertical reference axis of outer tube, called $\beta$. Five configurations with nomenclature as SSA- $\beta$-n-I where SSA stands for straight semi-apical, $\beta$ is the inner tube reference angle which varies from 0 to 2 degrees, $\mathrm{n}$ is the configuration number and I stand for inverted face (valid only for configuration 3 and 5, in which the tube is inverted to face the impact). All of the configuration are impacted by a rigid plate with a constant velocity of $10 \mathrm{~m} / \mathrm{s}$. Deformation modes and energy absorption characteristics such as specific energy absorption (SEA), peak crushing force (PCF), mean crushing force (MCF) and crush force efficiency (CFE) are determined for each configuration. Results are compared with experimental results published in literature [19] and effectiveness of the proposed configuration is verified. A theoratical investigation on the effectiveness of semi-apical angle $\beta$ is also presented for different $\mathrm{L} / \mathrm{D}$ ratios where $\mathrm{L}$ is the length of the tube and $\mathrm{D}$ is the diameter for any conical tube.

\section{MATERIALS AND METHODS}

\subsection{Proposed Structural Configurations}

The proposed structural configuration is a set of two tubes with four through length stiffeners. The outertube is circularwith diameter $\mathrm{D}_{0}=80 \mathrm{~mm}$, length $\mathrm{L}=200 \mathrm{mmand}$ thickness $\mathrm{t}_{0}=1.5 \mathrm{~mm}$ while the inner tube is conical in shape with a semi-apical angle $\beta$ referred from the vertical axis of the tube, length $\mathrm{L}=200$ mmand thickness $\mathrm{t}_{\mathrm{i}}=\mathrm{t}_{0}$. Tubes are joined with four stiffeners of length $\mathrm{L}=200 \mathrm{~mm}$ along the radial direction as shown in Figure3. The configurations are five in number calledSSA-0-1,SSA-1-2,SSA-1-3-I,SSA-2-4 and SSA-2-5-I as shown in Figure 4.The configuration SSA-0-1 is the base configuration in this study which has been numerically investigated by Zhiliang Tang et al., [28] with configuration number as [CMC 1 X 4], along with multiple other configurations.In the third and fifth configuration name xxx-X-X-I, I show that the tubes are inverted to face the impact. Mass in each configuration is maintained same by adjusting the thicknesses of the stiffeners however, all the stiffeners are adjusted simultaneously to keep consistency in stiffeners and maintain symmetry. 


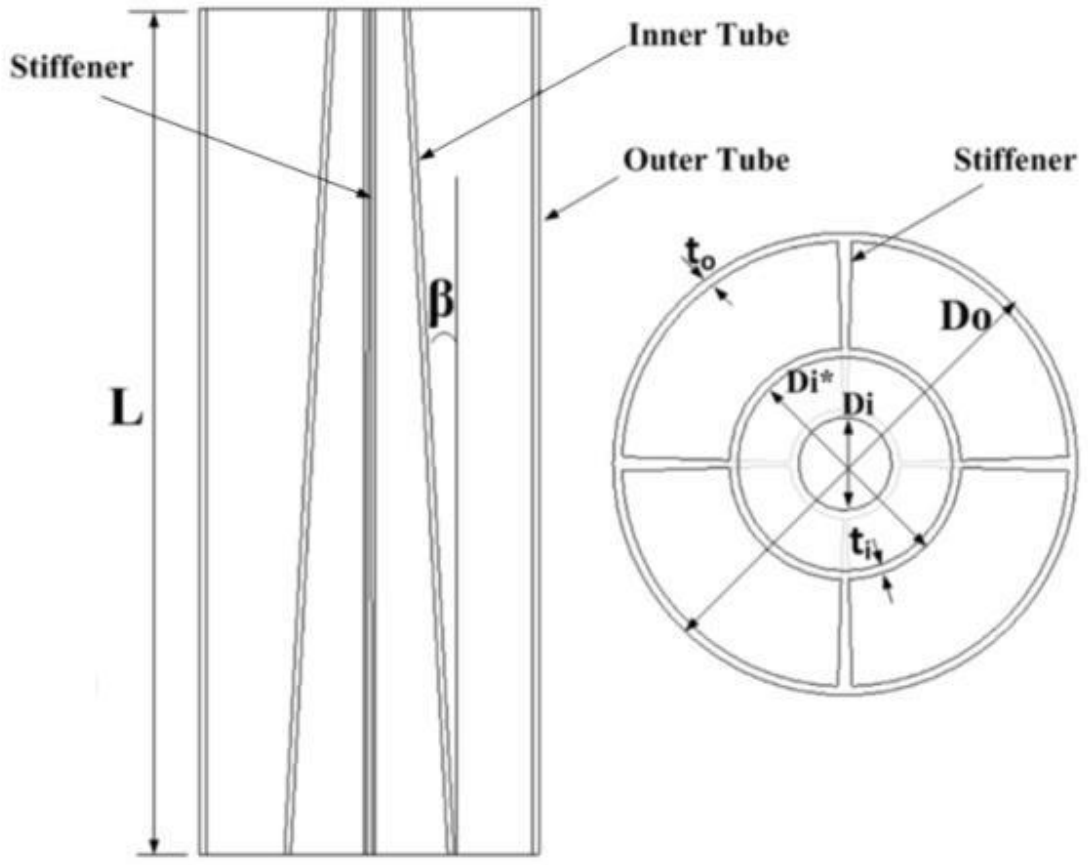

Figure 3: Schematic of proposed configuration.

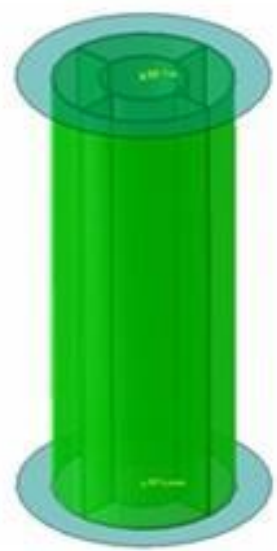

SSA-0-1

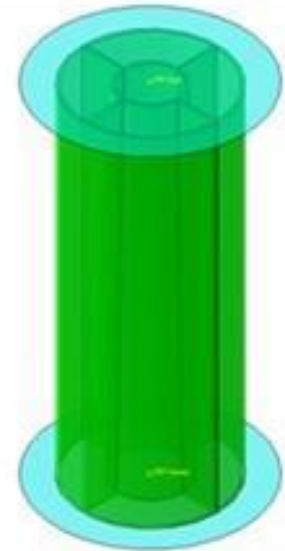

SSA-1-2

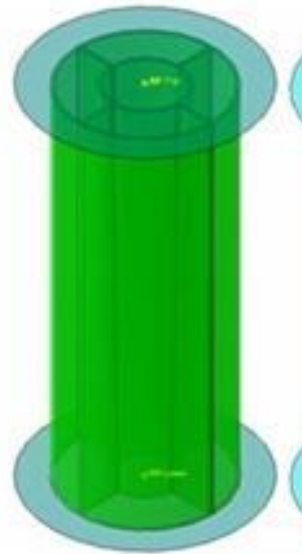

SSA-1-3-1

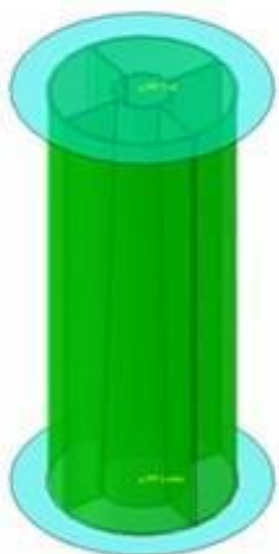

SSA-2-4

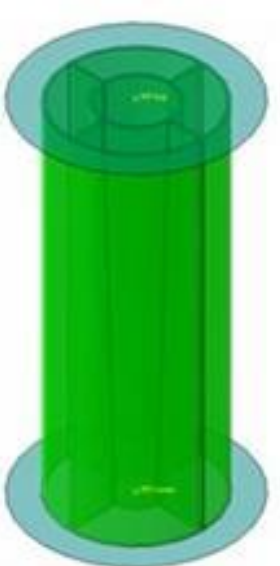

SSA-2-5-1

Figure 4:The proposed configurations.

\subsection{Theoretical Background}

The dynamic compressive behavior of thin-walled tubes is sensitive to inertia, strain rate effects and impact velocity. The deformation modes are roughly classified into two types: (1) a type called progressive folding collapse, where wrinkles are formed by local buckling of the tube wall and then the circular tube collapses while standing straight up as local buckles are formed progressively one after another (2) a global bending type called Euler buckling, where the circular tube flexes and collapses by buckling. For efficient impact energy absorption, it is preferable to design progressive buckling compression of circular tubes.

For a tube of length $\mathrm{L}$ and diameter $\mathrm{D}$, a semi-apical angle $\beta$ can be defined as:

$$
\beta=\tan ^{-1}(\mathrm{D} / 2 \mathrm{~L})
$$

For $\mathrm{L} / \mathrm{D}=1,0 \leq \beta \leq 26.57^{\circ}$ 
For $\mathrm{L} / \mathrm{D}>1,0 \leq \beta<26.57^{\circ}$

For $\mathrm{L} / \mathrm{D}<1,0 \leq \beta<90^{\circ}$

Where $\beta=0$ means a cylinderical tube.

As the $\mathrm{L} / \mathrm{D}$ ratio becomes lesser or equal to 1 , the buckling phenomenon becomes weaken and tubes failure is by crushing instead of buckling. For a sufficient long circular tube, the elastic critical stress for buckling is defined by Equation 2[29], while for a tube with some semi-apical angle, it is defined by Equation 3 ,

$$
\begin{aligned}
& \sigma_{\text {crit }}=\left(\mathrm{Et} / \mathrm{R} \sqrt{3\left(1-v^{2}\right)}\right) \\
& \sigma_{\text {crit }}=\left(\mathrm{Et} /((\mathrm{r} 1+\mathrm{r} 2) / 2) \sqrt{3\left(1-\mathrm{v}^{2}\right)}\right)
\end{aligned}
$$

Where $\mathrm{E}$ is Young's modulus, $\mathrm{t}$ is the thickness of the tube, $\mathrm{v}$ is Poisson's ratio, $\mathrm{R}$ is the radius of circular tube, $\mathrm{r} 1$ and $\mathrm{r} 2$ are the radius of upper and lower circular faces of the conical tube with semi-apical angle $\beta$.The average value of $\mathrm{r} 1$ and $\mathrm{r} 2$ is assumed in Equation 3 as equivalent to $\mathrm{R}$ value in Equation 2 because of small semi-apical angle $\beta$.Similarly, critical force for a conical tube can be described as by employing the surface area of a conical tube from Equation 3:

$$
\mathrm{F}_{\text {crit }}=\left(2 \pi \mathrm{Et}^{2} \operatorname{Cos}^{2} \beta / \sqrt{3\left(1-v^{2}\right)}\right)
$$

The response of critical buckling force against semi-apical angle is plotted in Figure 5.

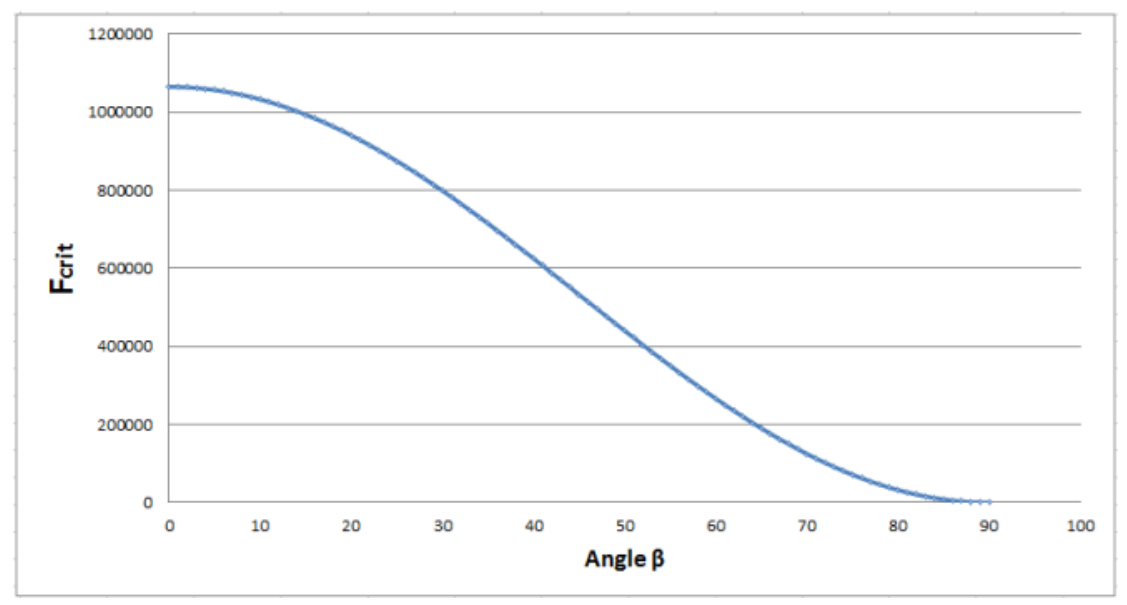

Figure 5: Critical buckling VS Angle $\beta$

The effect of impact velocity and slenderness ratio on dynamic buckling load for long columns can be determined as [30]:

$$
\alpha=a \cdot \lambda^{\mathrm{n}}+1
$$

Where $\alpha$ is the ratio of dynamic to static critical buckling load ratio, $\lambda$ is the slenderness ratio, $n$ denotes an exponent and a is a function that represents the velocity dependency on $\alpha$.Function can be approximated by a power law as shown in Equation 6:

$$
\mathrm{a}=\tau . \mathrm{V}^{\mathrm{m}}
$$


Where $\mathrm{m}$ and $\tau$ are constants and can be determined experimentally.

\subsection{Finite Element Modeling}

Crushing response and energy absorption of the bi-tubular multi-cell proposed configurations under axial impact loading is performed in ABAQUS explicit dynamic [31] package. The simulation boundary conditions in which the rigid moving plate strikes the tube configurations with an impact velocity of $10 \mathrm{~m} / \mathrm{s}$ as shown in Figure6.In configuration three and five, the tubes are inverted so that the inner conical tube's bigger diameter face is stricken by the rigid impact plate. The other face is constrained in all degrees of freedom using another rigid plate. In the FE model, the solid C3D8R element is used for the tube configurations, which is an 8-node linear brick element with reduced integration and hourglass control. The top and bottom plate is meshed using discrete rigid element. The top plate has an impact mass of 50kgs. After mesh convergence studies, an element size of $2.5 \mathrm{~mm}$ is found feasible and adopted in this study for all of the configurations. The contact between the top rigid plate and the tube is modeled as general explicit contact with tangential behavior being frictional using frictional coefficient of 0.2 and normal behavior being hard contact. The contact between the lowerplate and tube was defined as tie contact and to avoid the interpenetration while folding of the tube, a self-contact is also defined for all of the elements of the configuration. Material for all of the configurations is extruded aluminum AA $6060 \mathrm{~T} 4$ [28] with Young's modulus of 68.21MPa, yield strength of 80MPa and Poisson's ratio of 0.3. The stress strain curve of the selected material is shown in Figure 7. The load, material configurations and boundary conditions are identical for all of the configurations.

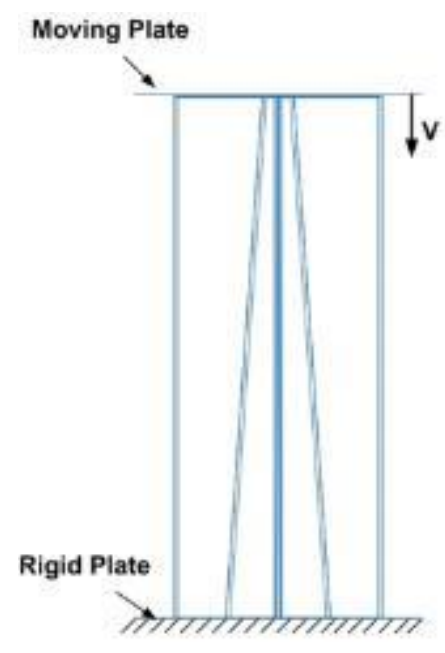

Figure 6: FE boundary conditions

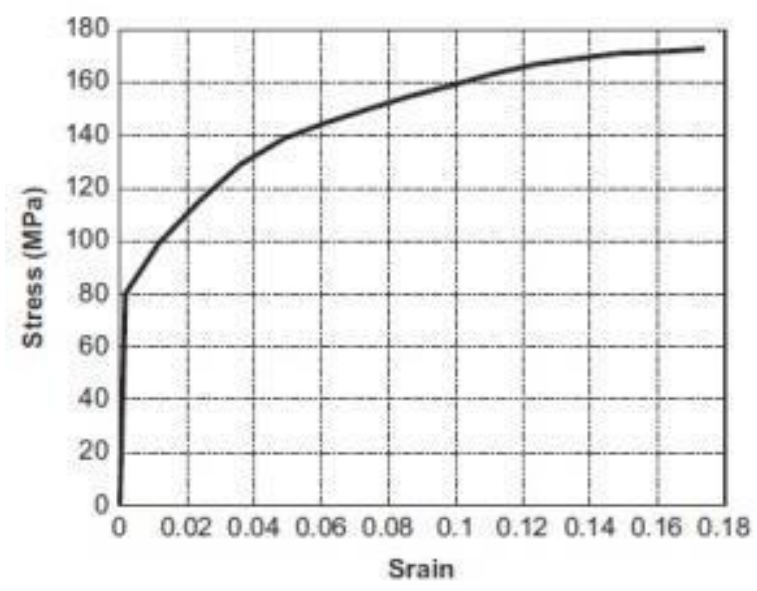

Figure 7: Stress-strain curve of AA 6060 T4 [28]. 


\subsection{Energy Absorption Indicators}

Energy absorption indicators which are presented in this study to show the crush mechanics and energy absorption characteristics of the tube configurations are defined in this section. These indicators can be determined from the load-displacement curve as follows:

\section{Energy Absorption (EA):}

It is the area under the force-displacement curve during axial crushing and can be calculated as [10]:

$$
\mathrm{EA}=\int \mathrm{Fd} \delta
$$

where $\mathrm{F}$ is the crushing force and $\delta$ is the crushing distance.

Specific Energy Absorption (SEA):

It is the ratio of absorbed energy to the total mass $(\mathrm{m})$ of the structure. It is used to compare the energy absorbers and can be calculated as [10]:

$$
\mathrm{SEA}=\int \mathrm{Fd} \delta / \mathrm{m}
$$

\section{Mean Crush Force (MCF):}

It is obtained by dividing the energy absorbed (EA) by crushing distance $\delta$ as shown in Equation 9 [10]:

$$
\mathrm{MCF}=\mathrm{EA} / \delta
$$

where $\mathrm{F}$ is the crushing force and $\delta$ is the crushing distance.

Crush Force Efficiency (CFE):

It is the ratio of the mean crushing force to the peak crushing force and can be calculated as [10]:

$$
\mathrm{CFE}=\mathrm{F} \mathrm{m} / \mathrm{Fp}
$$

where $\mathrm{F}_{\mathrm{m}}$ is the mean crushing force and $\mathrm{F}_{\mathrm{p}}$ is the peak crushing force. For an ideal energy absorber, the CFE is $100 \%$.

\section{RESULTS AND DISCUSSION}

\subsection{Validation of the FE Modeling}

Finite element model adopted for this study is verified against the Zhang and Zhang [19] work for the energy absorption characteristics of multi-cell column as shown in Figure 8. Numerous configurations are experimentally crushed by Zhang and Zhang including straight circular tube, circular triple cells and circular quadruple cells by keeping the length of all of the tubes as $120 \mathrm{~mm}$ with a thickness of $1.2 \mathrm{~mm}$. The straight circular tube with material AA6061 O is selected as the reference tube for the validation of finite element modeling approach adopted in the current study. The validation is performed by keeping the structural geometry, material properties, mesh parameters and the boundary conditions exactly the same as was in [19]. It is clear from the Figure 8 that the results obtained in this study are identical to the referred work [19]. Once the model is validated the similar analysis can be performed for all of the proposed configurations in this study. 


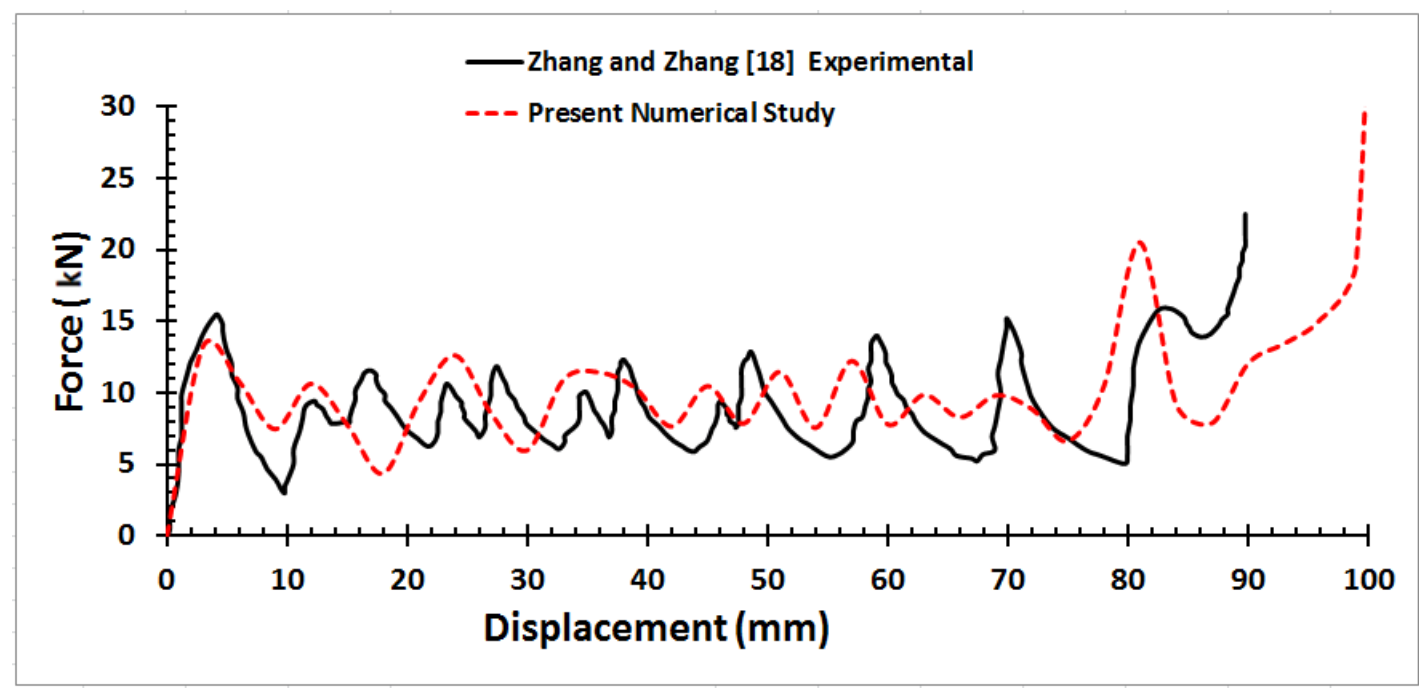

Figure 8: Validation of FE Modeling with experimental work of Zhang and Zhang [19].

\subsection{Deformation Modes}

Deformation patterns for the proposed configurations at different instances of time during analysis are plotted in Figure 9. In majority of the cases, diamond pattern is dominant while mixed mode is also observed during the axial deformation of the tube structures. Deformation lobes start from the impacted face in SSA-1-2 and SSA-2-4 while inverted configurations showed a complex deformation pattern. SSA-1-3-I followed the axisymmetric lobes formationfor half of the deformation scheme, later being converted to mixed mode. SSA-25-I got simultaneous deformation lobes from impacted face and opposite face, later showing huge lobes formation from the fixed face. Deformation modes describe the energy absorption capabilities of the tubes and are a major contributor for the high or low peak force, smoothness of the load-displacement curve and final behavior of the defined structure.
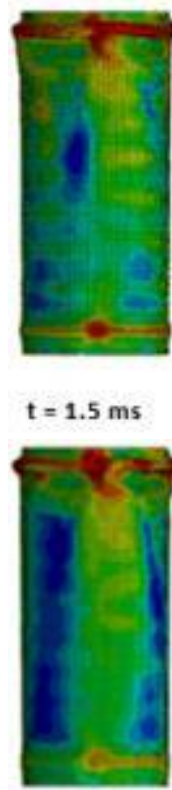

$t=1.5 \mathrm{~ms}$

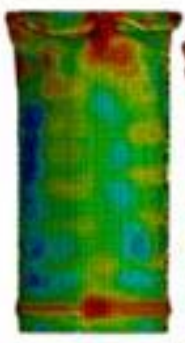

$t=3 \mathrm{~ms}$

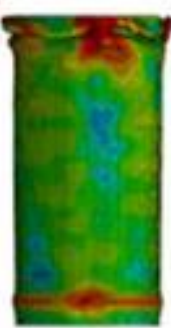

$\mathrm{t}=3 \mathrm{~ms}$

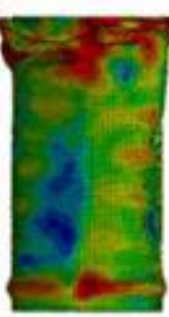

$t=4.5 \mathrm{~ms}$

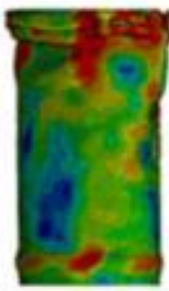

$\mathrm{t}=4.5 \mathrm{~ms}$

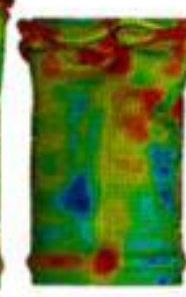

$t=6 \mathrm{~ms}$

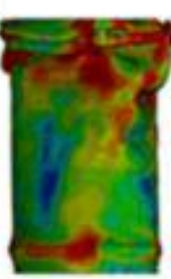

$\mathrm{t}=6 \mathrm{~ms}$

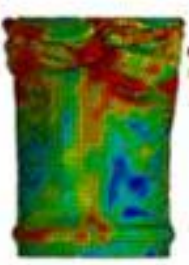

$\mathrm{t}=7.5 \mathrm{~ms}$

$\mathrm{t}=9 \mathrm{~ms}$

$t=10.5 \mathrm{~ms}$

$t=12 \mathrm{~ms}$ $\mathrm{t}=13.5 \mathrm{~ms}$

(a) DeformationPatternof SSA-1-2

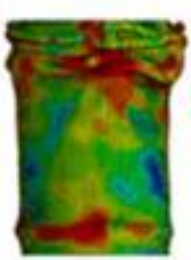

$t=7.5 \mathrm{~ms}$
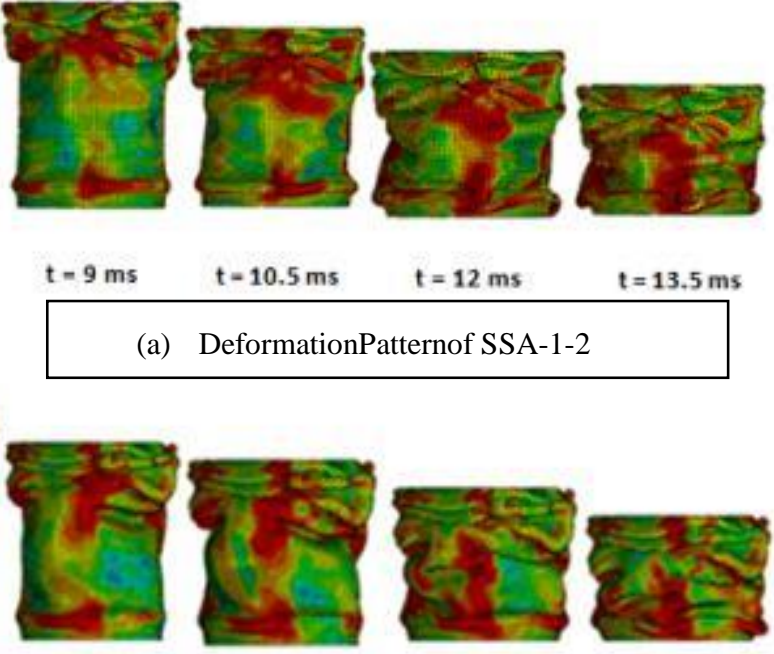

$\mathrm{t}=9 \mathrm{~ms}$

$\mathrm{t}=10.5 \mathrm{~ms}$

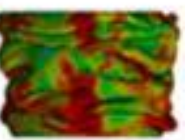

$t=13.5 \mathrm{~ms}$ 

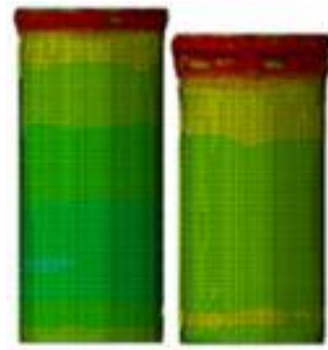

$t=1.5 \mathrm{~ms}$

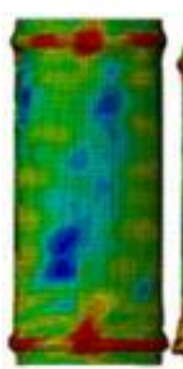

$t=1.5 \mathrm{~ms}$ $t=3 \mathrm{~ms}$

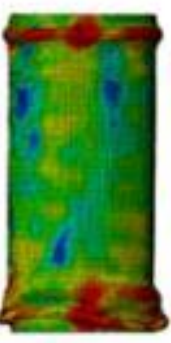

$\mathrm{t}=3 \mathrm{~ms}$

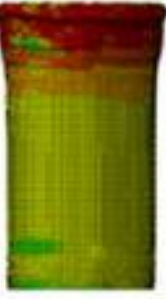

$t=4.5 \mathrm{~ms}$

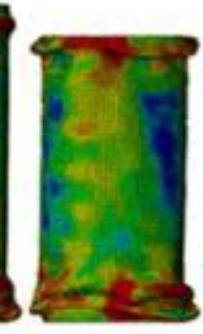

$\mathrm{t}=4.5 \mathrm{~ms}$

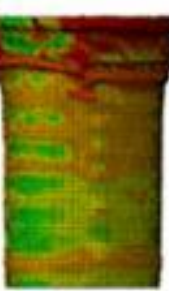

$t=6 \mathrm{~ms}$

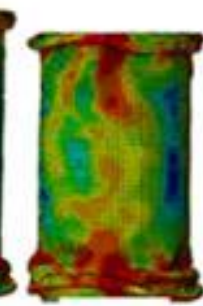

$t=6 \mathrm{~ms}$

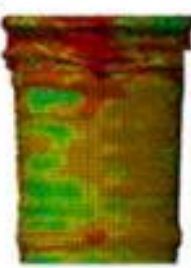

$t=7.5 \mathrm{~ms}$

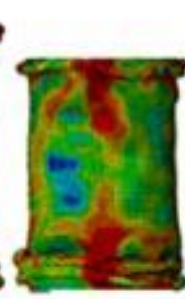

$t=7.5 \mathrm{~ms}$ (b) Deformation Pattern of SSA-2-4

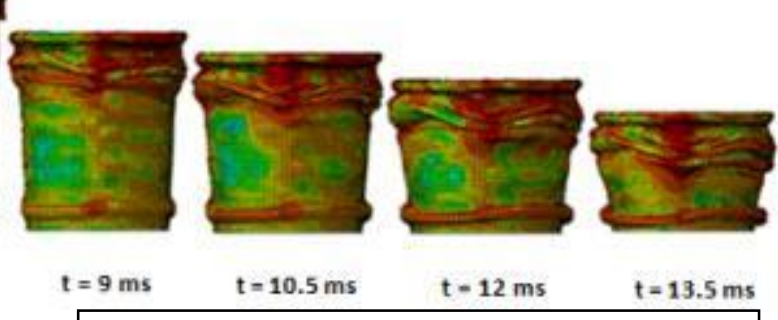

(c) Deformation Pattern of SSA-1-3-I

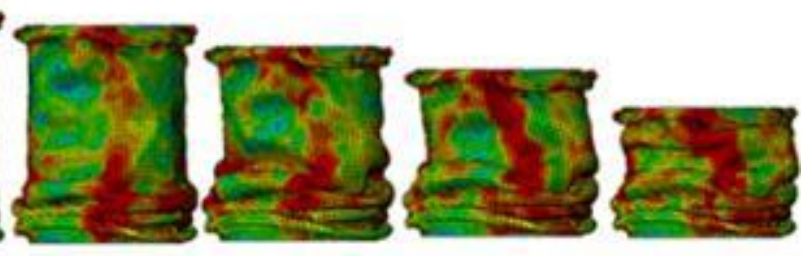

$t=9 \mathrm{~ms} \quad \mathrm{t}=\mathbf{1 0 . 5} \mathrm{ms} \quad \mathrm{t}=12 \mathrm{~ms} \quad \mathrm{t}=13.5 \mathrm{~ms}$

(b) DeformationPatternof SSA-2-5-I

Figure 9: Deformation modes of proposed configurations (a) SSA-1-2 (b) SSA-2-4 (c) SSA-1-3-I (d) SSA-2-5-I.

\subsection{Energy Absorption Indicators}

Force-displacement curves for all of the proposed configurations are shown in Figure 10. Energy absorption performance of a structure can be determined from force-displacement curves by getting the required parameters for the evaluation of the energy absorption indicators described by the Equation7 to Equation 10.

The force-displacement curve for the reference configuration SSA-0-1 is assumed to be ideal in nature and all other curves are evaluated for peak force and smoothness in comparison with this curve. It is clear from the curves that semi-apical angled configurations are very similar in nature with reference configurations while inverted configurations like SSA-1-3-I and SSA-2-5-I are wavy in nature, describing the relaxation during fold formation. This shows that the inversion gives a negative influence for the stress waves. Energy absorption, PCF, MCF, SEA and CFE are compared for different configurations in Figures 11 to 13. Energy absorption for the tube with $\beta$ zero degree that is SSA-0-1 is chosen as reference to monitor the effectiveness of all other configurations. The energy absorption parameter EA is found to be $7503.1 \mathrm{~J}$ which is also the lowest as compared to the 8216.07J, 8036.21J, 8299.75J and 7676.53J for configurations SSA-1-2, SSA-1-3I, SSA-2-4 and SSA-2-5-I, respectively. The SSA-2-4 configuration shows an increase of 9.6\% in EA with just a small $\beta$ of 2 degrees. It can also be concluded from Figure 11 that inversion of the face can decrease the EA drastically as the $\beta$ keeps increasing from 1 to 2 degrees. 


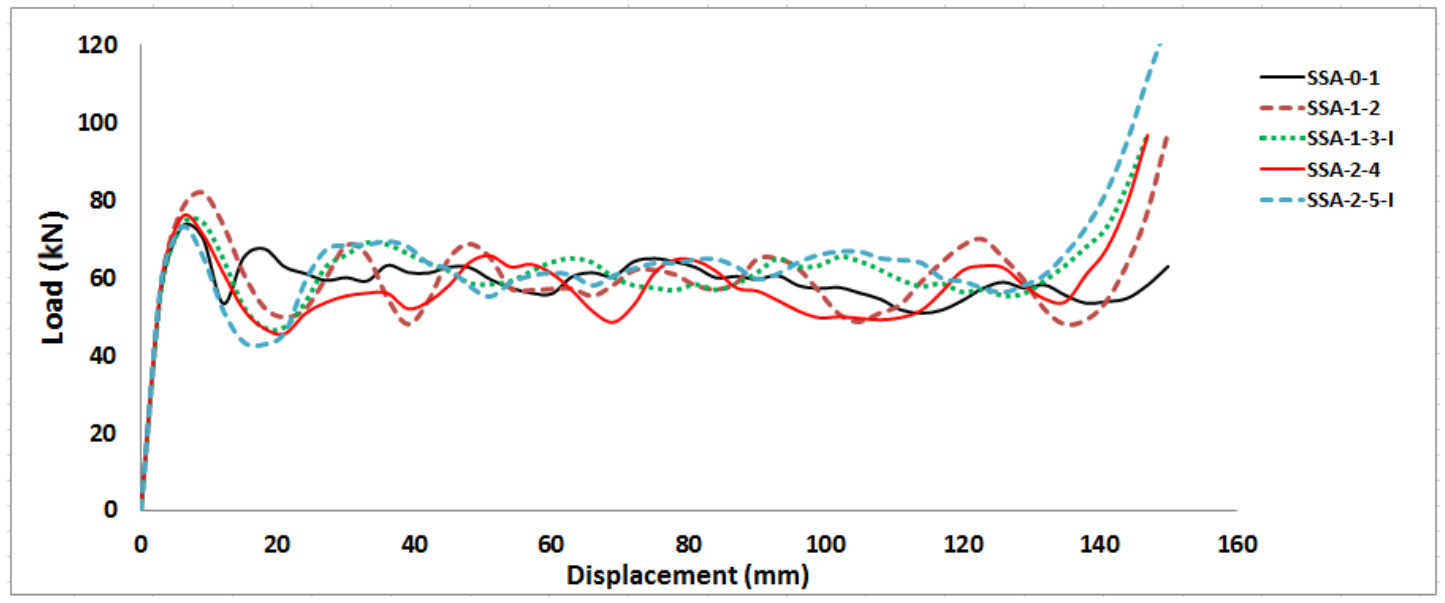

Figure 10: Force-displacement curve for proposed configurations.

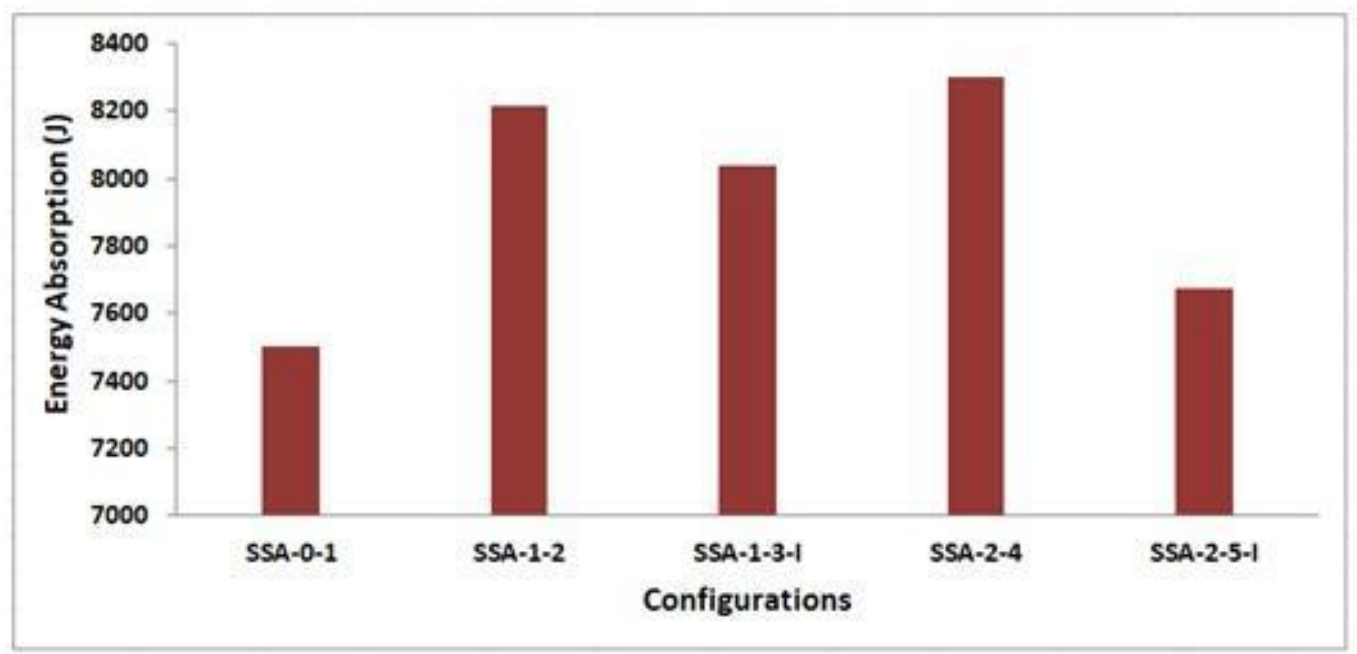

Figure 11: Energy absorption for proposed configurations.

Energy absorption indicators like PCF, MCF and SEA are compared in Figure 12 for proposed configurations. It is clear from the plot that the highest peak force is for SSA-1-3-I configuration with a value of $81.94 \mathrm{kN}$ and the lowest PCF is for reference configuration SSA-0-1 with a value of $71.43 \mathrm{kN}$. Introduction of semi-apical angle $\beta$ gave a slight increase in PCF which is $74.3 \mathrm{kN}$ and $73.04 \mathrm{kN}$ for configurations SSA-12 and SSA-2-4 respectively. However, PCF is lower with higher semi-apical angle with a difference of $2.2 \%$ higher for SSA-2-4, 3.86\% higher for SSA-1-2 when compared to reference configuration SSA-0-1. Inversion of the face showed results contrary toSSA-1-2 and SSA-2-4, withPCF increase. The PCF relationship is inverse in nature for increasing semi-apical angle $\beta$ for inverted configurations as compared to SSA-1-2 and SSA-2-4. Similar observations are found for MCF and SEA for all of the configurations. MCF and SEA is highest for SSA-2-4 with an increase of $11 \%$ and $3.5 \%$ respectively. 


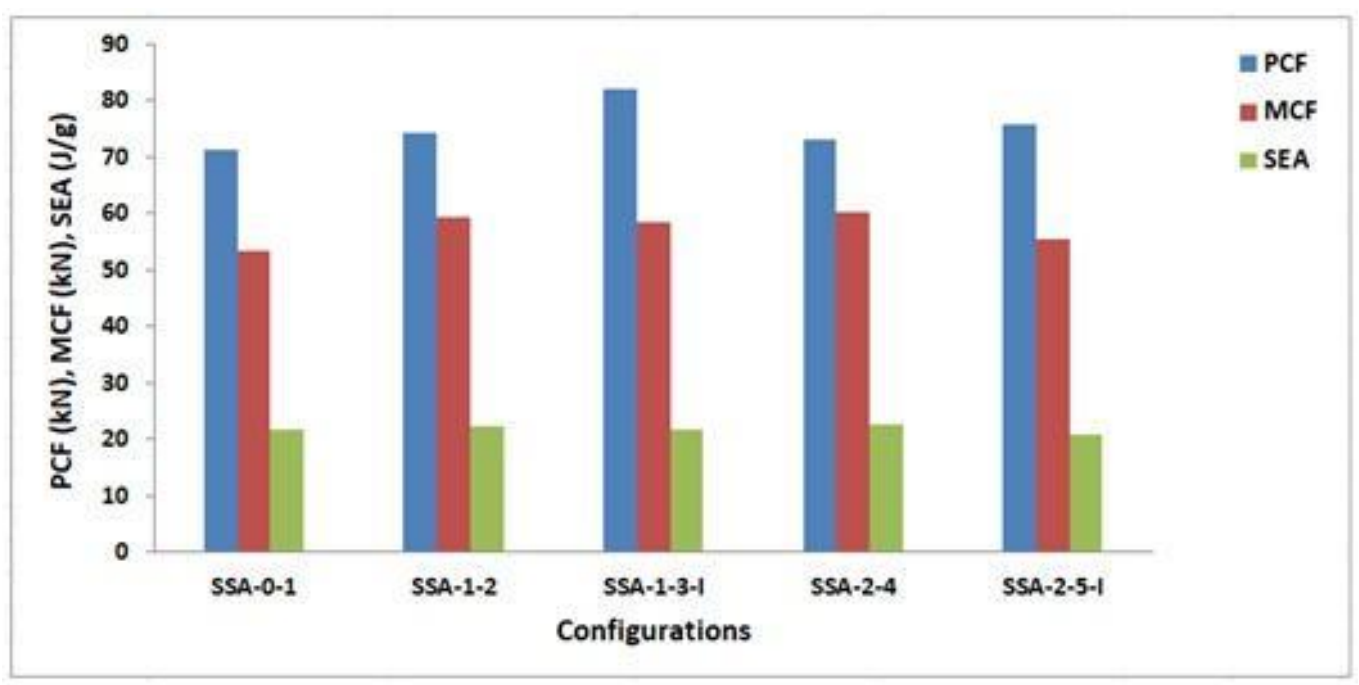

Figure 12: Energy absorption indicators; a comparison.

An ideal energy absorber's CFE must approach to $100 \%$ as it is an indicator of the performance consistency of the structure. Figure 13 shows the CFE for all of the configurations adopted in this study. Semiapical angle showed its effect on CFE as well. The highest CFE is for SSA-2-4 configuration with a value of $82 \%$ which is $8.53 \%$ higher as compared to SSA-0-1. SSA-1-2 showed a CFE about $80 \%$ which is the second highest in the list while inverted configurations showed a CFE of 71 and 73\% for SSA-1-3-I and SSA-2-5-I respectively which is lower than the reference configuration value of $75 \%$. A semi-apical angle converts the stress wave in two directional paths, giving the bending stiffness contribution along with plastic folding, hence increasing the efficiency while inverting can give the pre-mature bending which reduces the CFE of the inverted configurations.

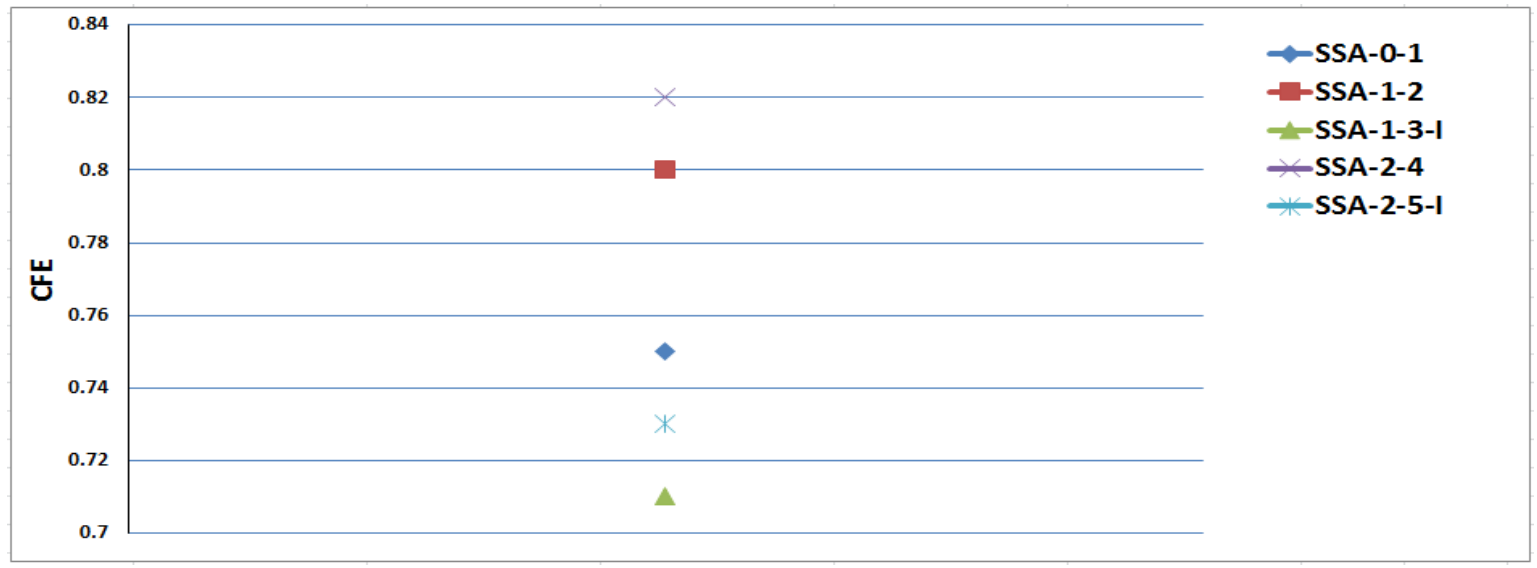

Figure 13: CFE for proposed configurations.

\section{CONCLUSION}

In this study, semi-apical angle which gives a reduced critical buckling load for a single tube is utilized in bitubular configuration in a unique way that the outer tube is kept cylindrical while the inner tube is optimized with a small semi-apical angle. The proposed configuration generally showed an improved performance in energy absorption especially with a small semi-apical angle as compared to straight bi-tubular stiffened configuration. SSA-2-4 with a semi-apical angle of 2 degrees showed the best performance among the simulated configurations with an increase of EA, MCF, SEA and CFE whose contribution is higher than the reference configuration SSA-0-1 with parameters' increase value of $9.6 \%, 11 \%, 3.5 \%$ and $8.53 \%$, respectively. A small semi-apical angle also helped to keep the PCFlow as it showed an increase of just $2.2 \%$ with reference configuration. When the face of the tube is inverted as shown in SSA-1-3-I and SSA-2-5-I, the energy absorption parameters dropped drastically due to the possible reason of dominant bending failure. 
Also the deformation starts at both ends simultaneously to reduce the energy absorption efficiency. The force-displacement curve of the configurations along with better energy absorption indicators is smoother and comparative to the reference tube configuration of Zhiliang Tang et al., work [28]. However, the inverted configurations curve shows variation of the force value about the mean which is not desirable.

The study can be extended to normalize the effectiveness of the semi-apical angle for long and relatively shorter tubes. The semi-apical angle can also be evaluated for the outer tube with a configuration in which the angle is opposite in reference to the describedangle in inner tube.

\section{ACKNOWLEDGEMENT}

The authors gratefully acknowledge the financial supports from National Natural Science Foundation of China under Grants 11472226 and 11672248.

\section{BIBLIOGRAPHY}

[1] SHAKERI, M., MIRZAEIFAR, R., SALEHGHAFFARI,S.,"New insights into the collapsing of cylindrical thin-walled tubes under axial impact load”,ProcIntMechEng, PartC. J MechEngSci,v. 221, pp. 117, 2007.

[2]FAUZAN, D., SHAHRUM, A., A., K.,ARIFFINC, Z.,et al., "Multi objective optimization of foam-filled circular tubes for quasi-static and dynamic responses", Latin American Journal of Solids and Structuresv, v.12, pp.1126-1143, 2015.

[3] LU, G., YU, T., Energy absorption of structures and materials, Woodhead Publishing Limited, 2003.

[4] JONES, N., Structural impact, Cambridge University Press, 1989.

[5] ABRAMOWICZ, W., JONES, N.,"Dynamic progressive buckling of circular and square tubes”,International Journal of Impact Engineering, v. 4, n.4, pp. 243-70, 1986.

[6] GUILLOW, S.R., LU,G., GRZEBIETA, R.H.“Quasi-static axial compression of thin-walled circular aluminiumtubes”,International Journal of Mechanical Sciences, v. 43, pp. 2103-2123, 2001.

[7] MAMALIS, A. G., MANOLAKOS, D. E., BALDOUKAS, A. K. Viegelahn:Thin-Walled Struct. v. 12 pp. 17-34, 1991.

[8] MAMALIS, A.G., MANOLAKOS, D.E., BALDOUKAS,A.K., et al., "Energy dissipation and associated failure modes when axially loading polygonal thin-walled cylinders", Thin-Walled Structures, v. 12, pp. 1734, 1991.

[9] ABRAMOWICZ, W., JONES, N.,"Dynamic axial crushing of square tubes”,International Journal of Impact Engineering, v. 2, n.2, pp. 179-208, 1984.

[10] ZAHRAN,M.S., XUE,P., ESA, M.S., "Novel approach for design of 3D-multi-cell thin-walled circular tube to improve the energy absorption characteristics under axial impact loading”, International Journal of Crashworthiness, v.22, n.3, 2016.

[11] KIM, H.S., "New extruded multi-cell aluminum profile formaximum crash energy absorption and weight efficiency",Thin Wall. Struct., v. 40, pp. 311-327, 2002.

[12] MARSOLEK, J., REIMERDES, H.G., "Energy absorption ofmetallic cylindrical shells with induced non-axisymmetricfolding patterns, Int. J. Impact Eng. v. 30, pp. 1209-1223, 2004.

[13] KINDERVATER, C., "Aircraft and helicopter crashworthiness:Design and simulation in Crashworthiness of TransportationSystems: Structural Impact and Occupant Protection",Springer Science C Business Media, pp. 525-577, 1997.

[14] CHEN,W., WIERZBICKI, T., "Relative merits of single-cell, multi-cell and foam-filled thin-walled structures in energy absorption”,Thin-Walled Struct., v. 39, n.4, pp. 287-306, 2001.

[15] JUSUF, A., DIRGANTARA, T., GUNAWAN, L., et al., "Crashworthiness analysis of multi-cell prismatic structures",Int. J. Impact Eng., v. 78, pp. 34-50, 2015.

[16] BAI, Z., GUO, H., JIANG, B., et al., "A study on the mean crushing strength of hexagonal multi-cell thin walled structures",Thin Wall. Struct., v. 80, pp. 38- 45, 2014.

[17] HONG, W., FAN, H., XIA, Z., et al., "Axial crushing behaviors of multi-cell tubes with triangular 
lattices",Int. J. Impact Eng., v.63, pp. 106-117, 2014.

[18] NIA, A.A., PARSAPOUR, M., "Comparative analysis of energy absorption capacity of simple and multi-cell thin walled tubes with triangular, square, hexagonal and octagonal sections",Thin Wall. Struct., v. 74, pp. 155-165, 2014.

[19] ZHANG,X., ZHANG, H., “Axial crushing of circular multi-cell columns”,Int. J. Impact Eng., v. 65, pp. 110-125, 2014.

[20] WIERZBICKI, T., BHAT, S.U., ABRAMOWICZ,W., et al., "Alexander revisited-a two folding elements model of progressive crushing of tubes",Int J Solids Struct., v. 29, pp. 3269-88, 1992.

[21] AHMAD, Z., THAMBIRATNAM, D.P., "Dynamic computer simulation and energy absorption of foam-filled conical tubes under axial impact loading",ComputStruct., v. 87, pp. 186-97, 2009.

[22] XUE, P., X, T., YU, X.,et al., "Flat-topped conical shell under axial compression”, Int J Mech Sci., v. 43, pp. 2125-45, 2001.

[23] BAGHER,M., AZIMI,B., ASGARI, M.,"A new bi-tubular conical-circular structure for improving crushing behavior under axial and oblique impacts",International Journal of Mechanical Sciences, v. 105, pp.253-265, 2016.

[24] MAHMOODI, A., SHOJAEEFARD,M.H., GOOGARCHIN, H.S., "Theoretical development and numerical investigation on energy absorption behavior of tapered multi-cell tubes",Thin-Walled Structures, v.102, pp.98-110, 2016.

[25] AKTAY, L., KROPLIN, B.H., TOKSOY,A.K., et al., "Finite element and coupled finite element/smooth particle hydrodynamics modeling of the quasi-static crushing of empty and foam-filled single, bi-tubular and constraint hexagonal and square packed aluminum tubes",J Mater Des., v.29, n.5, pp. 952-62, 2008.

[26] SEITZBERGER, M., RAMMERSTORFER, F.G., DEGISCHER,H.P., et al., "Crushing of axially compressed steel tubes filled with aluminum foam",Acta Mech., v. 125, pp. 93-105, 1997.

[27] SALIMI,E., MOLATEFI, H., ALI REZVANI, M., et al., "Improving Collision Energy Absorption In High Speed TrainBy Using Thin Walled Tubes", IJR International Journal of Railway, v. 96, n.3, pp. 85-89, 2013.

[28] TANG, Z., LIU, S., ZHANG, Z., "Analysis of energy absorption characteristics of cylindrical multi-cell columns",Thin-Walled Structures, v. 62, pp. 75-84, 2013.

[29] CHEN, D. H., Crush Mechanics of Thin-Walled Tubes, CRC Press, 2016.

[30] MIMURA, K., UMEDA, T., "Effects of Impact Velocity and Slenderness Ratio on Dynamic Buckling Load for Long Columns", International Journal of Modern Physics B, v. 22, n. 31 e 32, pp. 5596-5602, 2008.

[31] ABAQUS., Version 6.15. Abaqus analysis user's manuals, Simulia, Dassault Systems, Rising Sun Mills, 166 Valley Street, Providence, RI 02909-2499, USA.

\section{ORCID}

$\mathrm{XuePu}$

Muhammad Kamran

Naveed Ahmed

Ahmad Abdul GhaffarHanif
https://orcid.org/0000-0002-5239-027X

https://orcid.org/0000-0001-5083-9806

https://orcid.org/0000-0002-6538-6237

https://orcid.org/0000-0002-7166-7203 